OPEN ACCESS

Citation: F. Orlandi, A. Ranfa, L. Ruga, C. Proietti, M. Fornaciari (2021) Meteorological and Salix species (S. acutifolia, S. smithiana, S. viminalis) phenological trends in central Italy. Italian Journal of Agrometeorology (1): 81-88. doi: 10.36253/ijam-822

Received: January 15, 2020

Accepted: January 17, 2021

Published: August 9, 2021

Copyright: (C2021 F. Orlandi,A. Ranfa, L. Ruga, C. Proietti, M. Fornaciari. This is an open access, peer-reviewed article published by Firenze University Press (http://www.fupress.com/ijam) and distributed under the terms of the Creative Commons Attribution License, which permits unrestricted use, distribution, and reproduction in any medium, provided the original author and source are credited.

Data Availability Statement: All relevant data are within the paper and its Supporting Information files.

Competing Interests: The Author(s) declare(s) no conflict of interest.

\section{Meteorological and Salix species (S. acutifolia, S. smithiana, S. viminalis) phenological trends in central Italy}

\author{
Fabio Orlandi*, Aldo Ranfa, luigia Ruga, Chiara Proietti, Marco \\ FORNACIARI \\ Department of Civil and Environmental Engineering, University of Perugia, Borgo XX \\ Giugno 74, 06121 Perugia, Italy \\ *Corresponding author: fabio.orlandi@unipg.it; ORCID: 0000-0003-4021-8664
}

\begin{abstract}
Plant phenology, through opportune observing and interpreting techniques can be useful to interpret the eventual plant vegetative and reproductive adaptation to climate changes. Some plants of Salix acutifolia Willd., S. smithiana Willd. and S. viminalis $L$. were considered in a phenological garden in central Italy for analysing their phenological growth stages according to the International gardens network indications during a 10-year period (2008-2017) which allowed us to realize some preliminary trend analyses. The 3 Salix species showed different behaviours in the same cultivation area. S. acutifolia manifested no trend for spring and autumnal phases, $S$. viminalis presented low significant trends while S. Smithiana was that with the more evident tendencies for all the considered vegetative phases during the study period. The reproductive phase (BBCH 65) showed no significant trend for any Salix species during the study period not being influenced by the different meteorological variables and suggesting that photoperiod in this case may play an important role. The more evident phenological trends were represented for 2 Salix species by the advance of the leaf development during spring and by the progressive delay of the senescence during the last part of the summer, with the fallen leaves phase that was recorded averagely 2 weeks later during the last years of the study period.
\end{abstract}

Keywords: phenological stages, Salix species, climate.

\section{INTRODUCTION}

Phenological monitoring of the vegetative and reproductive plant developments recorded during the annual cycle of different species utilized as biomonitors in sampling campaigns allow to interpret the relationships between the principal environmental factors and biological response of spontaneous and agricultural plants (Menzel et al. 2006; Orlandi et al. 2007).

Plant phenology, which refers to the growth cycle of plant species in different regions, can be highly affected by climatic changes above all considering focal development stages such as the start and the end of the growing season or the flowering (Kramer 1994; Bergant et al. 2002; Schleip et al. 
2008; Chuine et al. 2010; Gordo and Sanz 2010; Aguilera et al. 2014). In deciduous arboreal species, the flowering and leafing dates at the end of winter-early spring are influenced by the chilling amounts for buds and the successive forcing temperature summations (after break dormancy) as an adaptation for preventing the beginning of vegetative development once frosts during February-march in Mediterranean area may be very dangerous (Larcher 2003).

The purpose of this study was to describe and interpret the phenological vegetative and reproductive growth stages of some clone plants of Salix spp in comparison to the climate characteristics recorded in a "Garden" of central Italy included in the International Phenological Gardens network (IPG) and consequently not subjected to invasive agronomic techniques. The garden located near Rieti, central Italy, and managed by personnel of the University of Perugia (UNIPG) contains from 2005 to nowadays some indicator species, common to the IPG network (Schnelle and Volkert 1964; Orlandi et al. 2007) obtained from mother plants received from the German Weather Service, the European coordinator for the distribution of IPG clones.

Usually in these types of Gardens, the principal area is dedicated to the International section where plants common to the large part of the European phenological gardens are present. Other sections are the "National" and the "Local" ones where often plants of economic interest for the cultivation area are present. The principal aim of this study was to show the presence of eventual trends of the main meteorological variables and Willow plants vegetative and reproductive phenological dates during a 10-year period (from 2008 to 2017) monitoring also the current climatic changes and observing potential adaptations of the plants through morphological variations during the different growing seasons.

\section{MATERIALS AND METHODS}

\section{The phenological gardens}

The first gardens in Italy were planted from'90 in accordance with the common indications established by the phenological gardens pioneers in central Europe some decades in advance (Orlandi et al. 2007, 2014). The first 2 gardens representing Italy in IPG network were those of S.Pietro Capofiume (near the city of Bologna) and Perugia (Umbria Region, central Italy) hosting national plants and some indicator species common to all IPGs in an area of Mediterranean climate with a subcontinental influence. The Perugia garden is managed by the University of Perugia that during 2005 planted other
3 gardens in Rieti area (Lazio Region) at different altitudes (about $350 \mathrm{~m}, 1100 \mathrm{~m}$ and $1700 \mathrm{~m}$ a.s.l.). The garden considered in the present investigation is that located in the Rieti plain (Lat: N 42 $25^{\prime} 30^{\prime \prime}$; Long: E 1249'45"; Alt. about $350 \mathrm{~m}$ a.s.l.) in an area of about $2,000 \mathrm{~m}^{2}$.

In the cited garden, since first cultivation period, 5 Willow trees of different Salix species (S. acutifolia Willd., S. smithiana Willd. and S. viminalis L.) were planted considering their importance as guide plants in north-central European gardens.

\section{Climate data}

The meteorological data essential to realize consistent statistical interpretation of biological responses to environmental variables were available directly from a meteorological station located nearby the same garden. In the Rieti plain, the meteorological station was managed by the "Apennines Centre of Terminillo Mountain" of the University of Perugia (http://www. cat.unipg.it). The variables considered were: Maximum and minimum Temperature (Tmax-Tmin in ${ }^{\circ} \mathrm{C}$ ), Precipitation (Rain in $\mathrm{mm}$ ), Relative Humidity ( $\mathrm{RH} \%$ ), Solar Radiation (SR in $\mathrm{cal} / \mathrm{cm}^{2}$ ). The daily data of the 10-year considered period (2008-2017) were elaborated to obtain weekly summations to be used in the trend analysis.

\section{Phenological methodology}

The international phenological key of interpretation $(\mathrm{BBCH})$ was utilized to obtain comparable values from the observations made in the monitored garden (Chmielewski and Rötzer, 2001; Saska \& Kuzovkina 2010). The following phenological phases were considered for the vegetative cycle of the Salix species: $\mathrm{BBCH} 02$, beginning of bud swelling; $\mathrm{BBCH} 11$, first true leaf; $\mathrm{BBCH} 95$, the leaves are mostly fallen (50\% of leaves fallen). Moreover, the flowering phase was observed monitoring the BBCH65 phase (full flowering). In each garden, the observations were conducted on three individuals of the five present plants for each Salix species, to limit random variability and the mean date for the onset of each phenophase was calculated as an average considering contemporarily the three plants. Two principal periods "First leaf development-FLD" and "Leave presence period-LPP", were calculated and evaluated during the study years in the two areas. FLD was calculated as the weeks number between $\mathrm{BBCH} 02$ and $\mathrm{BBCH} 11$, while LPP as the weeks between $\mathrm{BBCH}$ 11 and 95. 
Relationships between meteorological requirements and the phenological phases

To evaluate the potential meteorological tendencies of the last decade in the study area, the weekly summations of the principal meteorological variables (Tmax, Tmin, Rain, RH, SR) were calculated year by year during the "FLD" and "LPP" periods. Statistical analyses were realized between the phenological periods and the meteorological variables amounts considering the 10 years of the study.

A correlation analysis was realized considering the length of the two periods "FLD" and "LPP" and the amounts of the weekly values of the principal meteorological variables during the same periods. The more significant correlated variables were considered to realize a multiple regression analysis between FLD-LPP periods as dependent variables and meteorological data as independent variables. Moreover, a trend analysis was done using nonparametric Mann-Kendall tests, for monotonic positive or negative trends. In particular, positive $\mathrm{Z}$ values demonstrate a trend for a delay in the biological data, while negative $Z$ values indicate a trend for anticipation (earlier) of the historical series of each phase. To test the presence of meteorological tendencies, the weekly summations of TMax, Tmin, Rain, RH, SR, were calculated for three different periods determined on the base of the phenological phases recorded. The first period, precedent the beginning of bud swelling, from the $1^{\text {st }}$ of January of each year to the mean date of $\mathrm{BBCH} 02$ (calculated during the 10-year period). The second period, between mean bud swelling date (BBCH02) and first true leaf (mean $\mathrm{BBCH} 11$ date). The third period, between first true leaf and leaves fallen (from the mean dates of $\mathrm{BBCH} 11$ to the BBCH95) during the study period. Finally, the trend analysis was also realized for the weekly summations of the meteorological variables (positive $Z$, increased; negative $Z$, decreased), for both of the phenological gardens. To estimate the true slope of an existing trend (as change per year), the Sen nonparametric method was used (Sirois 1998). For the significance levels, the following symbols are used: ${ }^{*}$, trend at $\mathrm{p}<0.05$; ${ }^{* *}$, trend at $\mathrm{p}<0.01$; and ${ }^{* * *}$, trend at $\mathrm{p}<0.001$. The Excel template application MAKESENS version 1.0 (Salmi et al. 2002) was used for the Mann-Kendall trend analysis.

\section{RESULTS}

In Fig. 1 the trend analysis of the weekly summations of the solar radiation calculated from 1 January to 2 conventional dates of the year $\left(13^{\text {th }}\right.$ and $39^{\text {th }}$ week) are shown.
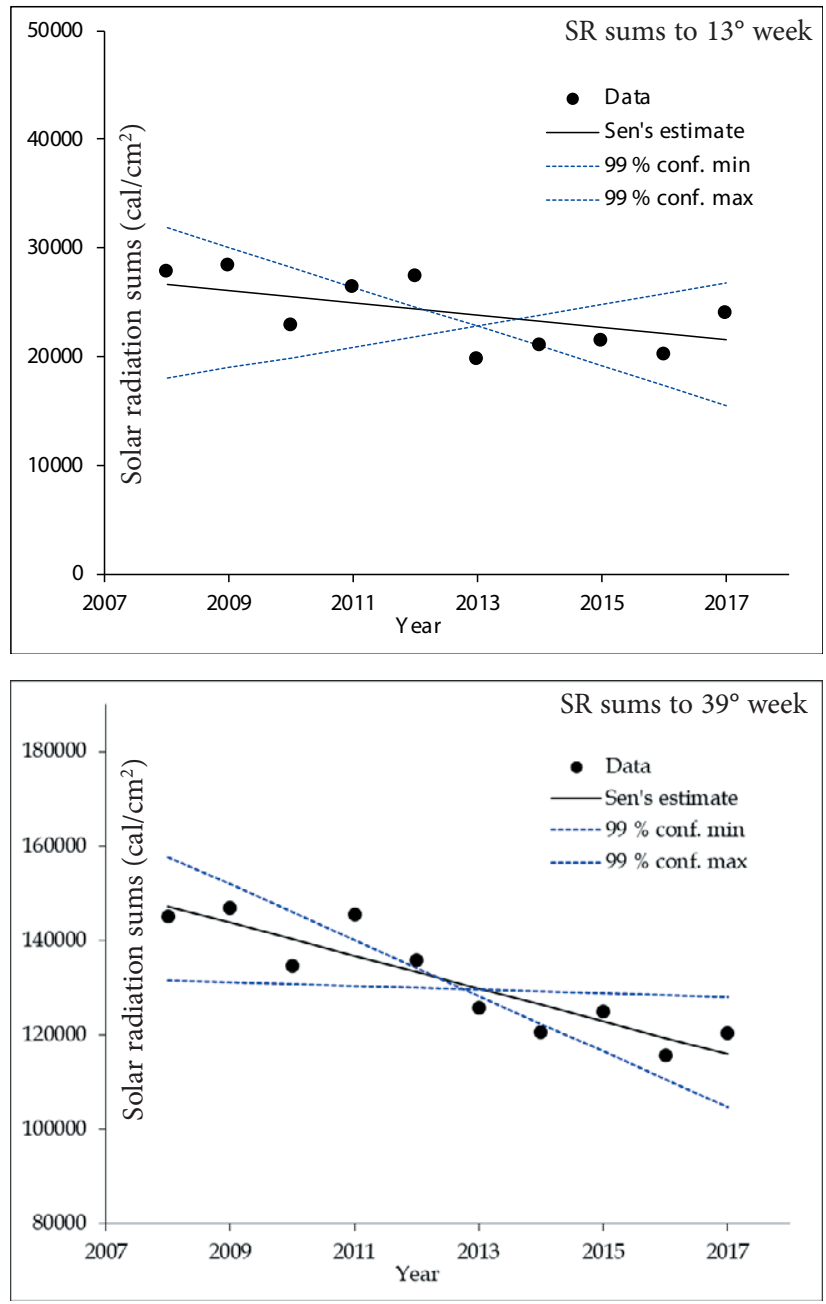

Fig. 1. Trend analysis of the weekly summations of the solar radiation $\left(\mathrm{cal} / \mathrm{cm}^{2} /\right.$ day) calculated to 2 conventional dates $\left(13^{\text {th }}\right.$ and $39^{\text {th }}$ week of the year). In the chart the original data points of the time series, the Sen's estimator for a linear trend, the lines for $99 \%$ confidence intervals are shown.

The $13^{\text {th }}$ week summations practically corresponded to the average date of BBCH11 phase for all the Salix species in the study area while $39^{\text {th }}$ week summation is just precedent to the average $\mathrm{BBCH} 95$ phase occurrence. In the 10-year series no trends have been shown by quite all the different meteorological variables. Only the SR summations to the $39^{\text {th }}$ week evidenced a significant negative trend (Test $\mathrm{Z}-2.50$, Significance ${ }^{*} \mathrm{p}<$ 0.01 ) indicating a temporary reduction of this variable amounts particularly over the summer periods in the study area. The calculation of the average value of the 2 sub-periods 2008-2012 and 2013-2017 showed a solar radiation reduction of about $14 \%$ which determined the trend analysis result although the small size of the sample should do not lead to misleading interpretations. 
In Table 1 the trend analyses (Mann-Kendall test $\mathrm{Z}$ coefficients) are reported for the considered phenological phases that for the meteorological variable summations recorded to the same phases dates. S. acutifolia not presented significance for any phases so neither meteorological amounts were calculated to its development dates.

On the other hand, both Salix smithiana that viminalis evidenced some valuable results although conditioned by the low number of years considered in the trend analysis and therefore to validate with subsequent analyses.

However, S. smithiana presented significant trends during the study period for $\mathrm{BBCH} 02-11$ and 95, also the two calculated periods "First leaf development-FLD" and "Leave presence period-LPP" showed high significance.

In particular, the beginning of bud swelling $(\mathrm{BBCH}$ 02) showed a low decreasing significant trend corresponding to a progressive advance, such as the successive phase, BBCH 11, even more evident ( $Z$ coefficient -2.68). The senescence phase, $\mathrm{BBCH} 95$, showed an increasing trend related to a progressive delay of the phenological dates with the consequences that FLD trend was significantly decreasing while LPP even more significantly increasing.
Salix viminalis showed the same trends of S. smithiana even if with lowest significance values, while $\mathrm{BBCH} 02$ presented no trends.

In Table 1 is also possible to evidence that considering S. smithiana, Tmin and Rain weekly summations from the first of January to BBCH_11 dates not showed any trends, while Tmax, and above all $\mathrm{RH}$ and SR presented significant values. Moreover, RH, Rain and Tmin from $1^{\text {st }}$ January to $\mathrm{BBCH} 95$ dates not evidenced any trend during the study period. As regard as Salix viminalis BBCH11, above all Tmin and Rain showed no trends but, in this case, also Tmax was not significant. Moreover, for this species the RH and Rain summations to $\mathrm{BBCH} 95$ dates showed no trends but also both the temperature variables showed not significant values.

In Table 2 the multiple regression analysis between phenological phases and LPP periods which previously showed significant trend, as dependent variables and meteorological data as independent ones for the Salix species were reported. The BBCH11 phase for both the species was better related with Tmin and RH, S. smithiana presented also Rain as important independent variable while $S$. viminalis SR. The BBCH95 phase and LPP period showed Tmax and $\mathrm{RH}$ as the more important variables to explain their variance during the study year.

Tab. 1. Trend analysis of the phenological phases/periods and meteorological variable amounts for two Salix species during the 10-year study period (2008-2017).

Mann-Kendall test $\mathrm{Z}$ coefficient

\begin{tabular}{|c|c|c|c|c|c|}
\hline \multicolumn{3}{|c|}{ Salix smithiana } & \multicolumn{3}{|c|}{ Salix viminalis } \\
\hline & Test Z & Signific. & & Test Z & Signific. \\
\hline BBCH_02 & -1.73 & + & & & \\
\hline BBCH_11 & -2.68 & $* *$ & BBCH_11 & -2.08 & * \\
\hline BBCH_95 & 2.11 & * & BBCH_95 & 1.70 & + \\
\hline FLD & -2.02 & * & FLD & -1.67 & + \\
\hline LPP & 3.26 & ** & LPP & 1.86 & + \\
\hline BBCH11_Tmax & -1.79 & + & BBCH11_Tmax & -1.35 & \\
\hline BBCH11_Tmin & -0.18 & & BBCH11_Tmin & 0.18 & \\
\hline BBCH11_Rain & -0.89 & & BBCH11_Rain & -0.89 & \\
\hline BBCH11_RH & -2.15 & * & BBCH11_RH & -1.55 & + \\
\hline BBCH11_SR & -2.50 & * & BBCH11_SR & -2.68 & ** \\
\hline BBCH95_Tmax & 2.33 & * & BBCH95_Tmax & 0.89 & \\
\hline BBCH95_Tmin & 0.89 & & BBCH95_Tmin & 0.18 & \\
\hline BBCH95_Rain & -0.36 & & BBCH95_Rain & -0.36 & \\
\hline BBCH95_RH & 0.18 & & BBCH95_RH & 0.00 & \\
\hline BBCH95_SR & -1.79 & + & BBCH95_SR & -1.79 & + \\
\hline
\end{tabular}

$+\mathrm{p}<0.05 ;{ }^{*} \mathrm{p}<0.01 ;{ }^{* *} \mathrm{p}<0.001$

$\mathrm{w} 1-\mathrm{w} 7=$ period precedent the beginning of bud swelling w8-w14 = period between bud swelling and first true leaf $\mathrm{w} 15-\mathrm{w} 43$ = period between first true leaf and leaves fallen 
Tab. 2. Multiple regression analysis between Phenological phases, FLD-LPP periods as dependent variables and meteorological data as independent variables for the Salix species.

\begin{tabular}{|c|c|c|c|c|c|c|c|}
\hline & $\mathrm{F}$ & $\mathrm{R} 2$ & Adj. R2 & Variable & Coeff. & $\mathrm{t}$ & Sig. \\
\hline \multicolumn{8}{|l|}{ Phenological Phases } \\
\hline \multirow[t]{4}{*}{ BBCH11 S. smithiana } & 84.84 & 0.977 & 0.965 & Constant & -2.183 & -2.184 & 0.072 \\
\hline & & & & Tmin & -0.017 & -2.947 & 0.026 \\
\hline & & & & RH & 0.017 & 15.545 & 0.000 \\
\hline & & & & Rain & -0.005 & -3.524 & 0.012 \\
\hline \multirow[t]{3}{*}{ BBCH95 S. smithiana } & 33.86 & 0.9063 & 0.880 & Constant & 8.204 & 1.815 & 0.091 \\
\hline & & & & $\operatorname{Tmax}$ & 0.035 & 7.855 & 0.000 \\
\hline & & & & $\mathrm{RH}$ & 0.004 & 4.452 & 0.003 \\
\hline \multirow[t]{4}{*}{ BBCH11 S. viminalis } & 52.9 & 0.964 & 0.945 & Constant & 2.600 & 2.126 & 0.078 \\
\hline & & & & $\operatorname{Tmin}$ & -0.014 & -2.531 & 0.045 \\
\hline & & & & $\mathrm{RH}$ & 0.009 & 5.978 & 0.001 \\
\hline & & & & SR & 0.000 & 3.688 & 0.010 \\
\hline \multirow[t]{3}{*}{ BBCH95 S. viminalis } & 26.83 & 0.885 & 0.852 & Constant & 10.562 & 2.375 & 0.049 \\
\hline & & & & $\operatorname{Tmax}$ & 0.025 & 5.974 & 0.001 \\
\hline & & & & $\mathrm{RH}$ & 0.003 & 3.770 & 0.007 \\
\hline \multicolumn{8}{|l|}{ Phenological Periods } \\
\hline \multirow[t]{3}{*}{ LPP S. smithiana } & 91.54 & 0.963 & 0.953 & Constant & -6.014 & -2.052 & 0.079 \\
\hline & & & & $\operatorname{Tmax}$ & 0.035 & 8.397 & 0.000 \\
\hline & & & & $\mathrm{RH}$ & 0.005 & 5.469 & 0.001 \\
\hline \multirow[t]{3}{*}{ LPP S. viminalis } & 50.82 & 0.936 & 0.917 & Constant & -7.417 & -1.985 & 0.087 \\
\hline & & & & $\operatorname{Tmax}$ & 0.036 & 8.720 & 0.000 \\
\hline & & & & RH & 0.005 & 4.168 & 0.004 \\
\hline
\end{tabular}

In Fig. 2 and 3, trend analysis of the BBCH11, BBCH95 and LPP during the 10-year study period for Salix smithiana and viminalis have been presented. If the BBCH11 dates are similar for the two Salix species, BBCH95 dates showed some differences with $S$. viminalis in advance of about 2 weeks.

\section{DISCUSSION AND CONCLUSION}

The 3 Salix species showed different behaviours in the same cultivation area. S. acutifolia manifested no trend for spring and autumnal phases, $S$. viminalis presented low significant trends while $S$. Smithiana was that with the more evident tendencies for all the considered vegetative phases during the study period.

The reproductive phase $(\mathrm{BBCH} 65$, data not published) showed no significant trend for any Salix species during the study period not being also influenced by the different meteorological variables. This result validated the hypothesis according to which photoperiod is one of the principals forcing variable to regulate the timing of growth cessation in temperate and boreal regions at the end of the summer and the flower structure matu- ration when the first leaves have been developed during spring (Johansson and Staiger 2015; Orlandi et al. 2005). The photoperiodic signal controlling seasonal growth in trees appears to be perceived in the leaves even if other environmental variables mostly winter and spring temperatures interact with it determining complex speciesspecific interactions making difficult to correctly interpret the phenomena (Singh et al. 2017).

In this sense, the photoperiod, mainly determined by a function of latitude and time of year, is insensitive to the climate change, except under very cloudy conditions, not allowing to flowering phenomena to manifest significant tendencies.

Moreover, the graphic interpretation of the trend analysis suggested as the trend of BBCH11 evidenced a narrower $99 \%$ confidence interval evidencing less uncertainty about the results in comparison to that of BBCH 95.

In particular, on the base of the obtained results, the shortening trend of the FLD period for the Salix species may be attributed to the significant progressive advance during the years of the first true leaf dates $(\mathrm{BBCH} 11)$ and to the substantial unchanging (or lowest changing) of the bud swelling beginning ( $\mathrm{BBCH} 02)$. 

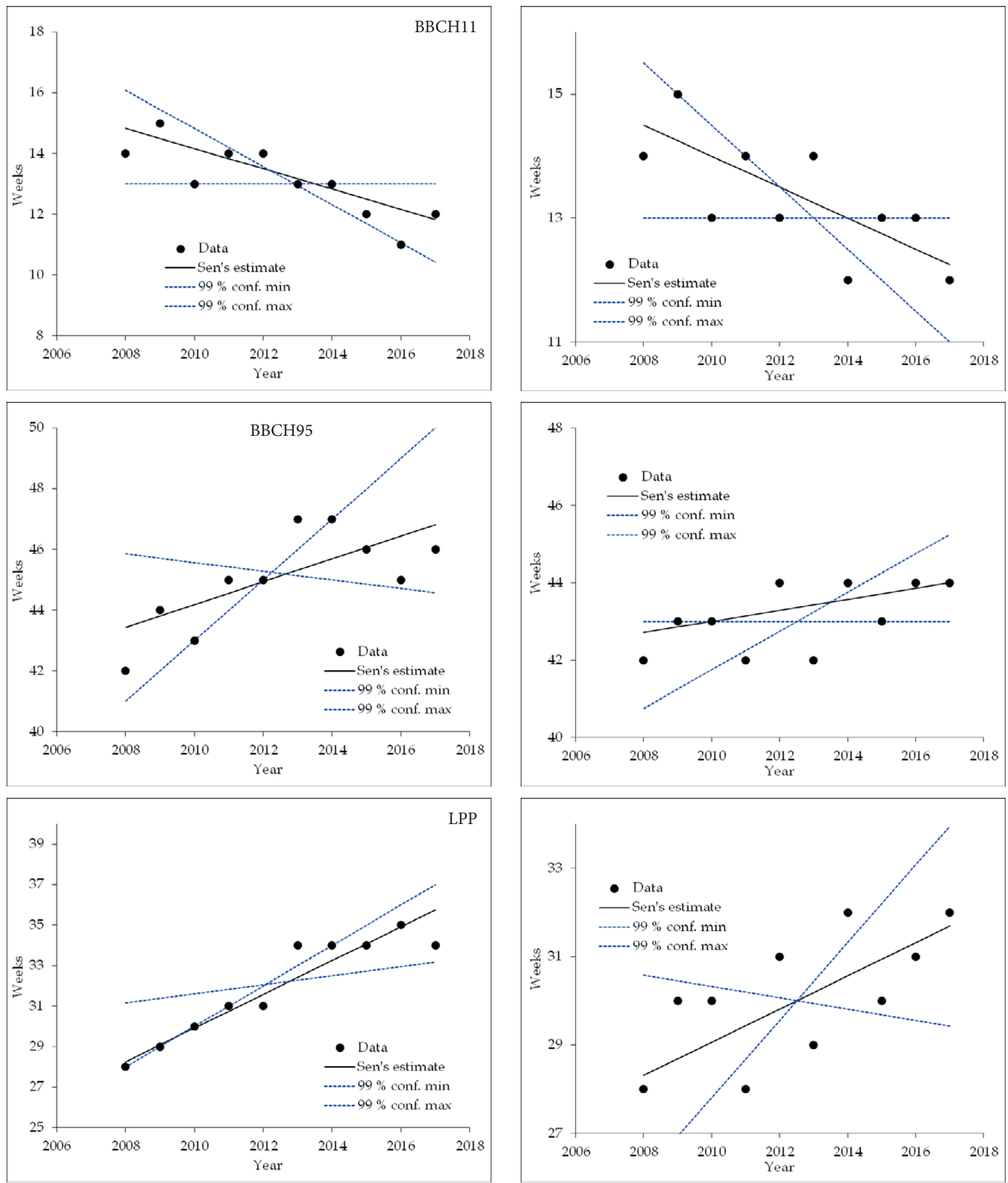

Fig. 2. Trend analysis of the BBCH11, BBCH95 and LPP during the 10 -year study period for Salix smithiana. In the chart the original data points of the time series, the Sen's estimator for a linear trend, the lines for $99 \%$ confidence intervals are shown.

Fig. 3. Trend analysis of the BBCH11, BBCH95 and LPP during the 10 -year study period for Salix viminalis. In the chart the original data points of the time series, the Sen's estimator for a linear trend, the lines for $99 \%$ confidence intervals are shown. 
The trend analyses realized for the meteorological variable summations recorded until the $\mathrm{BBCH} 11$ showed for S. smithiana Tmin and Rain as the variables without a significant trend. Moreover, RH, Rain and Tmin summations to $\mathrm{BBCH} 95$ not evidenced any trend.

In this case, we assumed that the no "trendy" meteo-variables for phenological phases with significant trends, were those which recorded "similar" summations year by year and so which more "regularly" influenced the plant development not being affected by the advance or delay of the same dates. In particular, BBCH11 of $S$. smithiana and viminalis was more influenced by "similar" chilling (Tmin) sums during the first weeks of the year, while BBCH95 by RH amounts.

Practically, the influence of Tmin but also of $\mathrm{RH}$, Rain and SR permitted to the young leaves to develop in shorter periods reaching in advance a complete development.

On the other hand, the trends of the LPP periods in both the areas were influenced by the simultaneous $\mathrm{BBCH} 11$ and 95 dates variation. In this sense, the lengthening of LPP may be related also to the progressive delay of the senescence phase during the years, with the BBCH95 that were recorded averagely 2 weeks later during the last years of the study period. The senescence delay of both S. smithiana and viminalis can be related to the high significant decreasing trend of SR summations to $39^{\text {th }}$ week, furthermore considering that SR manifested negative trend even if calculated to the $\mathrm{BBCH} 95$ dates themselves in progressive delay during the study years. In general, solar radiation have a limited impact on spring phenology compared with temperature and precipitation and its influence is mainly concentrated in August and September. Precedent investigations carried out as insolation sums also influence the phenological process in autumn, although their effects were largely biome dependent (Liu et al. 2016). The decline of August solar radiation may contribute to vegetation activities and accumulation of non-structural carbohydrate (Fu et al., 2014) in such a way that solar radiation reduction can postpone autumn senescence phenological phases.

\section{REFERENCES}

Aguilera F., Fornaciari M., Ruiz-Valenzuela L., Galán C., Msallem M., Ben Dhiab A., Díaz de la Guardia C., Trigo MM., Bonofiglio T., Orlandi F., 2014. Phenological models to predict the main flowering phases of olive (Olea europaea L.) along a latitudinal and longitudinal gradient across the Mediterra- nean region. International Journal of Biometeorology doi:10.1007/s00484-014-0876-7.

Bergant K., Kajfez-Bogataj L., Crepinsek Z., 2002. Statistical downscaling of GCM simulated average monthly air temperature to the beginning of flowering of dandelion (Taraxacum officinale) in Slovenia. International Journal of Biometeorology, 46: 22-32.

Chmielewski FM., Rötzer T., 2001. Response of tree phenology to climate change across Europe. Agriculture Forest and Meteorology, 108: 101-112.

Chuine I., Morin X., Bugmann H., 2010. Warming, photoperiods, and tree phenology. Science, 329: 277-278.

Fu YS., Campioli M., Vitasse Y., De Boeck HJ., Van den Berge J., AbdElgawad H., Janssens IA., 2014. Variation in leaf flushing date influences autumnal senescence and next year's flushing date in two temperate tree species. Proceedings of the National Academy of Sciences, 111(20): 7355-7360.

Gordo O., Sanz JJ., 2010. Impact of climate change on plant phenology in Mediterranean ecosystems. Global Change Biology, 16: 1082-1106.

Johansson M., Staiger D., 2015. Time to flower: interplay between photoperiod and the circadian clock. Journal of Experimental Botany, 66(3,1): 719-730.

Kramer K., 1994. Selecting a model to predict the onset of growth of Fagus sylvatica. Journal of Applied Ecology, 31: 172-181.

Larcher W., 2003. Physiological plant ecology: ecophysiology and stress physiology of functional groups. Biologia Plantarum, 47 (4): 500-513.

Liu Q., Fu YH., Zeng Z., Huang M., Piao S., 2016. Temperature, precipitation, and insolation effects on autumn vegetation phenology in temperate China. Global Change Biology, 22(2): 644-655.

Menzel A., Sparks TH., Estrella N. et al. 2006. European phenological response to climate change matches the warming pattern. Global Change Biology, 12: 19691976.

Orlandi F. et al. 2005. Bioclimatic requirements for olive flowering in two mediterranean regions located at the same latitude (Andalucia, Spain, and Sicily, Italy). Annals of Agriculture and Environmental Medicine, 12: 47-52.

Orlandi F., Bonofiglio T., Ruga L., Sgromo C., Romano B., Fornaciari M., 2007. Phenological investigations of different winter-deciduous species growing under Mediterranean conditions. Annals of Forest Science, 64: 557-568.

Orlandi F., Ruga L., Bonofiglio T., Romano B., Fornaciari M., 2014. Fifteen-year phenological plant species and meteorological trends in central Italy. Intenational Journal of Biometeorology, 58: 661-667. 
Salmi T., Maatta A., Anttila P., Ruoho-Airola T., Amnell T., 2002. Detecting Trends of Annual Values of Atmospheric Pollutants by the Mann-Kendall Test and Sen's Slope Estimates-The Excel Template Application Makesens". Finnish Meteorological Institute Publications on Air Quality No. 31, Helsinki, Finland.

Saska MM., Kuzovkina YA., 2010. Phenological stages of willow (Salix). Annals of Applied Biology, 156: 431437.

Schleip C., Rutishauser T., Luterbacher J., Menzel A., 2008. Time series modelling and central European temperature impact assessment of phenological records over the last 250 years, Journal of Geophysical Research, 113: doi:10.1029/2007JG000646.

Schnelle F., Volkert E. 1964. Internationale Phaenologische Garten. Agriculture Meteorology, 1: 22-29.

Singh, R.K., Svystun, T., AlDahmash, B., Jönsson, A.M., Bhalerao, R.P., 2017. Photoperiod- and temperaturemediated control of phenology in trees-A molecular perspective. New Phytol., 213: 511-524.

Sirois A., 1998. A Brief and Biased Overview of Time Series Analysis or How to Find that Evasive Trend. In WMO report No. 133: WMO/EMEP workshop on Advanced Statistical methods and their Application to Air Quality Data sets (Helsinki, 14-18 September 1998). 